\title{
Carbon Balance as a Physiological Basis for the Interactions of European Red Mite and Crop Load on 'Starkrimson Delicious' Apple Trees
}

\author{
A.H.D. Francesconi, A.N. Lakso ${ }^{1}$, J.P. Nyrop ${ }^{2}$, J. Barnard ${ }^{3}$, and S.S. Denning \\ Department of Horticultural Sciences, New York State Agricultural Experiment Station, Cornell University, \\ Geneva, NY 14456
}

Additional index words. Malus domestica, Panonychus ulmi, whole-canopy gas exchange, photosynthesis, fruit growth, integrated pest management, action threshold

\begin{abstract}
The hypothesis that carbon balance is the basis for differences in responses by lightly and normally cropped apple trees to European red mite (ERM) [Panonychus ulmi (Koch)] damage was tested. Mature 'Starkrimson Delicious' (Malus domestica Borkh.)/M.26 apple trees were hand-thinned to light (125 fruit/tree, about 20 t/ha) or normal (300 fruit/tree, about 40 t/ha) target crop levels and infested with low [ 100 cumulative mite-days (CMD)], medium (400 to 1000 CMD) or high (>1000 CMD) target levels of ERM. A range of crop loads and CMD was obtained. Mite population density, fruit growth, leaf and whole-canopy net $\mathrm{CO}_{2}$ exchange rates (NCER) were measured throughout the growing season of 1994. Leaf area and vegetative growth per tree were also measured. Yield and final mean fruit size were determined at harvest. Return bloom and fruiting were determined the following year. Total shoot length per tree was not affected by crop load or mite damage. ERM reduced leaf and whole-canopy NCER. Normally cropped trees showed fruit weight reduction earlier and more severely than lightly cropped trees with high mite injury. Variation in final fruit weight, return bloom and return fruiting was much better related to whole-canopy NCER per fruit than to CMD.
\end{abstract}

Many pests attack apple trees, including their fruit, which has resulted in a high use of pesticides in commercial orchards (Croft, 1978). Integrated pest management (IPM) methods have been developed and adopted to more efficiently use pesticides (Pedigo, 1989). Foliar feeders are especially suitable for IPM practices because pests can be controlled after a certain tolerable level of leaf injury occurs and before the crop is damaged (action threshold). Although effects of individual foliar feeders have been published for apple trees, results have been highly variable and the mechanism of apple tree responses to pest stress is poorly understood.

European red mite (ERM) (Panonychus ulmi) is a particularly problematic foliar pest of apples. Pesticides applied to control other pests destroy natural enemies of ERM, inducing mite outbreaks that can damage apple crops. Mites have become increasingly more difficult to control due to rapid development of resistance to pesticides (Croft et al., 1987; Lathrop, 1951).

ERM injury causes reduced leaf net $\mathrm{CO}_{2}$ exchange rate (NCER) (Campbell and Marini, 1990; Campbell et al., 1990; Lakso et al., 1996; Mobley and Marini, 1990) and can reduce yield, fruit size and quality, and return bloom (Ames et al., 1984; Beers and Hull, 1990; Beers et al., 1987; Chapman et al., 1952; Coghill, 1969; Hull and Beers, 1990; Lakso et al., 1996; Lienk and Minns, 1980; Light and Ludlam, 1972; Marini et al., 1994; Redl et al., 1991; Zwick et al., 1976). Results in these individual studies varied considerably, probably due to differences in the environment, the timing and

Received for publication 18 Oct. 1995. Accepted for publication 11 Apr. 1996. This research was funded in part by CAPES, Brazil (Graduate Fellowship for A.H.D.F.), Cornell IPM Program, Geneva, N.Y., and Arthur Boller Apple Research Grant. We gratefully acknowledge Joe Kovach for his guidance on IPM practices, Marty Van Kirk for special pesticide management of our experimental plots, Susan Brown for the use of her instruments, and Ian Merwin for editorial suggestions. Use of trade names does not imply endorsement of the products named nor criticism of similar ones not named. The cost of publishing this paper was defrayed in part by the payment of page charges. Under postal regulations, this paper therefore must be hereby marked advertisement solely to indicate this fact.

${ }^{1}$ To whom reprint requests should be addressed.

${ }^{2}$ Dept. of Entomology.

${ }^{3}$ Computer center. severity of the mite stress, and the physiological status of the tree, especially crop load (Lakso et al., 1996; Marini et al., 1994). Beers et al. (1987) reported reductions of fruit size and return bloom due to ERM regardless of leaf to fruit ratios on limbs used as experimental units. However, because carbohydrate transport occurs between branches after midseason (Hansen and Christensen, 1974; Palmer et al., 1991), branches should not be treated as independent units in that type of study. When whole trees were used as experimental units, interactions of crop load and ERM occurred. Greater decreases of fruit size, color and soluble solids concentration occurred in heavily cropped apple trees compared to lightly cropped trees (Ames et al., 1984; Marini et al., 1994; Zwick et al., 1976).

Quantifying the damage foliar pests cause to perennial crops is difficult. The perennial structures of these plants result from an integration of several factors (environment, pests, cultural practices, crop load and others) which leads to high variation among plants. Reserve carbohydrates and nutrients, and development of organs such as buds that begin differentiating the previous season lead to complex and not easily predictable carry-over effects of foliar pests on perennial crops such as apples. Furthermore, even though foliar pests injure the leaf, their impact is on the whole plant. The complexity and importance of scaling up from the leaf to a canopy level has been addressed previously by Lakso et al. (1996) and expanded in our study.

A mechanistic understanding of the relationships of plant, pest and environment is necessary to integrate impacts of foliar feeders on apple trees and fruit. Lakso et al. (1996) proposed that late season ERM effects on fruit development are mediated via the carbon balance of apple trees. Variation in final fruit weight on trees with various mite damage levels was better related to wholecanopy NCER per fruit, an expression of carbohydrate availability to the fruit, than to cumulative mite-days (CMD). In that study, however, trees had relatively heavy crop loads leading to a smaller mean fruit size for controls than is typically observed on lightly cropped 'Starkrimson Delicious'. To determine a response threshold valid under various cropping conditions, a broader range of fruit sizes and whole-canopy NCER per fruit needed to be evalu- 


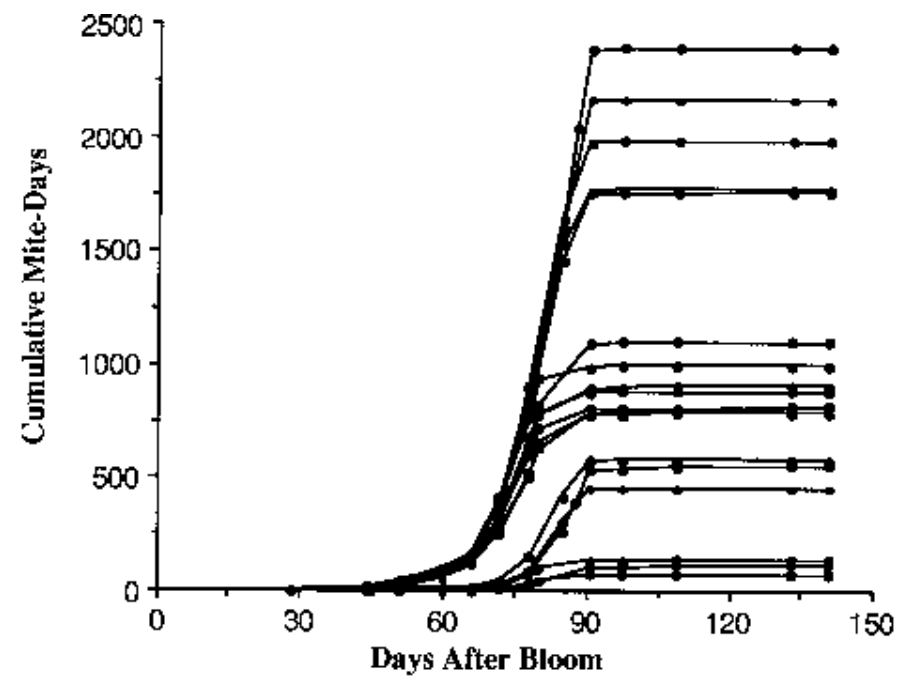

Fig. 1. Seasonal cumulative mite-day (CMD) curves of European red mite of eighteen mature 'Starkrimson Delicious' apple trees showing the range of CMD developmental patterns of all experimental trees.

ated. This was done in our experiment by varying crop loads, which affected carbohydrate demand, and mite populations, which affected carbohydrate supply.

If the carbon balance hypothesis for ERM effects on apples trees is valid, then interactions of effects of crop loads and ERM on apple trees should also be better related to whole-canopy NCER per fruit than to cumulative mite-days alone. Modeling and empirical data have shown that fruit growth reductions occur in heavily cropped trees late in the season probably due to limitations of carbohydrates (Lakso and Corelli Grappadelli, 1992; Lakso and Johnson, 1990; Lakso et al., 1995). The differential final fruit size response to ERM of apple trees with different crop loads (Ames et al., 1984; Marini et al., 1994) is consistent with a carbon balance mechanism. The physiological basis of this response was explored in our study.

The objectives of our study were 1) to determine when and how severely fruit growth rates of normally cropped trees are reduced by ERM damage in comparison to lightly cropped trees and 2) to determine if differences in responses of normally and lightly cropped apple trees to ERM are better related to differences in carbohydrate supply/demand than to differences in CMD alone.

\section{Materials and Methods}

In 1994, eighteen 12-year-old 'Starkrimson Delicious'/ M.26 central leader apple trees were selected for uniformity of size, canopy density and bloom density in two north-south rows at the New York State Agricultural Experiment Station, Geneva, N.Y. Trees were on average $2.1 \mathrm{~m}$ wide and $3.5 \mathrm{~m}$ tall and tree spacing was $3 \mathrm{~m}$ within rows and $4.6 \mathrm{~m}$ between rows. Normal fertilization, weed and disease control practices were used.

A factorial experiment was established with two target crop levels: light (125 fruit/tree) or normal (300 fruit/tree), and three target mite levels, expressed as CMD: low $(<100$ CMD), medium (400 to 1000 CMD) or high (>1000 CMD). Each tree was an experimental unit and there were three replications per treatment, in a completely randomized design. The target levels provided a range of crop load and mite levels appropriate for regression analyses of crop load and mite effects.

Crop load. At bloom (16 May), flowering and nonflowering spurs were counted on all trees. When fruit were about $14 \mathrm{~mm}$ in diameter ( $22 \mathrm{~d}$ after bloom (DAB), 6 June), trees were handthinned to about 125 or 300 fruit/tree ( 20 and 40 t/ha, respectively), leaving at most one fruit per cluster. Normally cropped trees produced a good commercial crop (40 t/ha). Crop load was later expressed in terms of number of fruit per trunk cross-sectional area (fruit/TCSA), number of fruit per leaf area and whole-canopy NCER per fruit.

Mite management and sampling. ERM populations were monitored at seven to ten day intervals, beginning 2 June, by randomly sampling 20 mature leaves per tree. June samples consisted of mature spur leaves only. From July on, samples included mature leaves situated at an intermediate position from 10 spurs and 10 extension shoots per tree. Leaves were brought to the laboratory and passed through a mite brushing machine (Leedom Engineering, Santa Clara, Calif.). Mites were collected on a glass plate containing a thin layer of a mixture of 1 part of polyoxyethylene sorbitan mono-oleate (Tween 80 ) and 2 parts of ethanol (95\%). Number of mites (protonymph, deutonymph and adult stages) per plate was counted under a dissecting microscope. Mite populations were estimated as CMD per leaf calculated with the following formula: mite-days $=\left[0.5\left(m p l_{p}+m p l_{c}\right)\right] \times \mathrm{d}_{c-p}$, where $m p l_{p}$ is the number of mites per leaf at the previous count, $m p l_{c}$ is the current number of mites per leaf, and $d$ is the number of days between counts (Beers et al., 1990). CMD is the sum of all mite-days throughout the season.

To ensure adequate mite populations, mites were transferred to target trees on 16, 21, and 22 June (31, 36, and 37 DAB), by attaching mite infested shoots throughout the canopy. Pesticides were used where appropriate to encourage or suppress mite populations and to control other pests. Superior oil (Superior 6E Oil) at $1 \%(\mathrm{v} / \mathrm{v})$ at tight cluster (5 May), propargite (Omite) at a rate of 1.1 $\mathrm{kg}$ active ingredient (a.i.)/ha, on 8 July and 4 Aug. (53 and 80 DAB), and formetanate hydrochloride (Carzol), on 15 Aug. (91

Fig. 2. Growth curves of 'Starkrimson Delicious' apples before and after the onset (arrow) of European red mite outbreak. The curves represent two lightly cropped trees (about 3 fruit/TCSA) and two normally cropped trees (about 4.4 fruit/ TCSA) submitted to low [69 and 115 cumulative mite-days (CMD) for light and normal crop, respectively] and high (1764 and 2394 CMD for light and normal crop, respectively) CMD. Each curve is the mean for 12 fruit/tree.

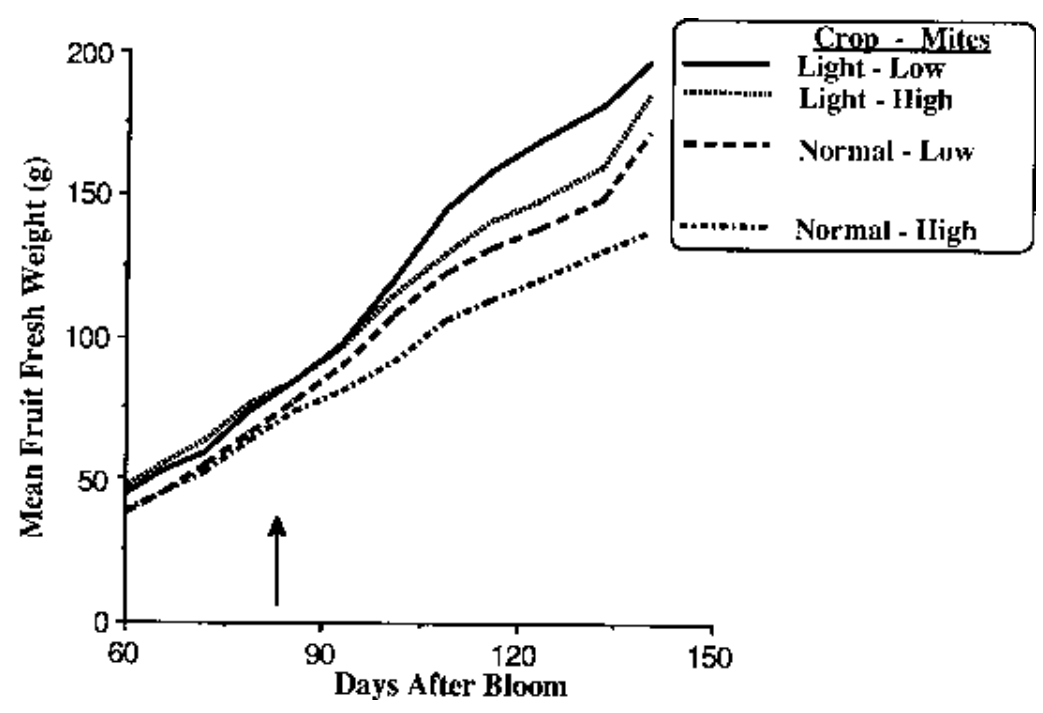




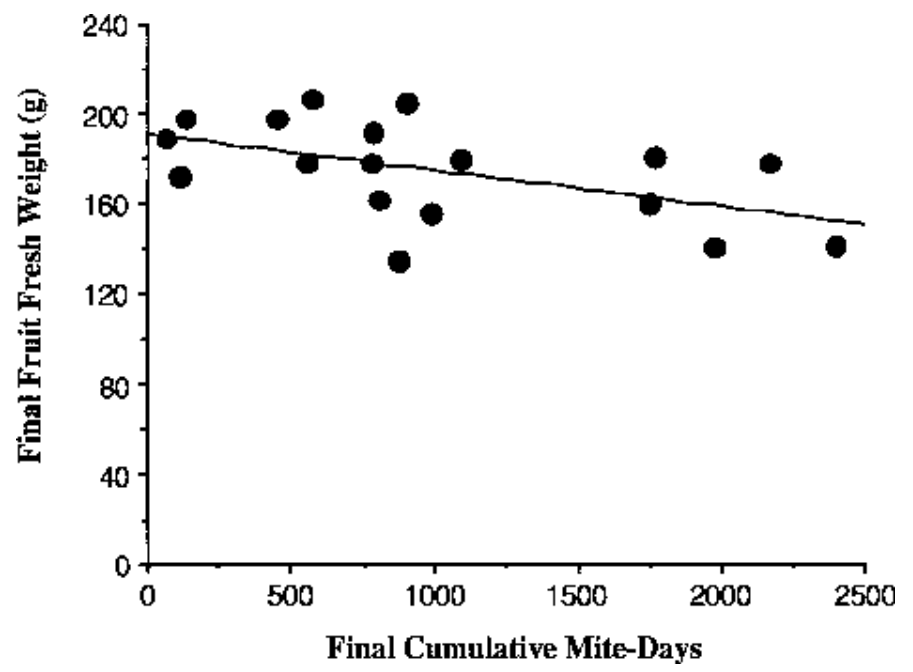

Fig. 3. Relationship between final fruit fresh weight and European red mite final cumulative mite-days (CMD) on 'Starkrimson Delicious' apple trees. Fruit weight $=190.57-0.016 \mathrm{CMD}, r^{2}=0.28, P<0.03$.

$\mathrm{DAB})$ at a rate of $1.3 \mathrm{~kg}$ a.i./ha, were applied on all trees designated for low mite numbers. Pyrethroid esfenvalerate (Asana XL) at rates of $0.18 \mathrm{~kg}$ a.i./ha (10 and $26 \mathrm{May}$ ) and $0.21 \mathrm{~kg}$ a.i./ha (23 June) was sprayed three times during the season on all trees in order to eliminate predatory mites in the orchard. When medium and high target levels of mites were reached, most trees were sprayed with propargite, at $1.1 \mathrm{~kg}$ a.i./ha, on either 4 or $9 \mathrm{Aug}$. (80 or $85 \mathrm{DAB}$ ). All trees were sprayed with formetanate hydrochloride on 15 and 22 Aug. (91 and 98 DAB) at $1.3 \mathrm{~kg}$ a.i./ha and on 2 Sept. (109DAB) at $1.6 \mathrm{~kg}$ a.i./ha to ensure no further mite damage. No other foliar feeding pests were abundant in the orchard.

Tree and fruit measurements. Twelve representative fruit throughout the canopy of each tree were tagged at $22 \mathrm{DAB}$ to monitor fruit growth with an electronic caliper (Mitutoyo, Japan) at seven to ten day intervals until harvest . A 20-fruit sample, with fruit in the whole range of measured fruit diameters, was collected from 'Starkrimson Delicious' buffer trees similar in size to the experimental trees on each day of fruit diameter measurements. Diameter, and fresh and dry weight of those 20 fruit were determined and used for regression estimation of seasonal fruit weight growth of the twelve tagged fruit, based on their fruit diameter measurements.

Trunk circumference of each tree was measured at $20 \mathrm{~cm}$ above the soil at early pink stage (4 May) and was used to calculate fruit/ TCSA.

Full canopy leaf area was estimated as follows. Total number of spurs, long shoots (longer than $5 \mathrm{~cm}$ ), and short lateral shoots $(<5$ $\mathrm{cm})$ per tree were counted. Based on two representative branches per tree, the average long shoot length and the percentage of long bourse shoots per tree were estimated. Short spurs per tree were calculated as the difference between the total number of spurs and the estimated number of long bourse shoots per tree. Thirty spurs with short bourses and short laterals were randomly measured on each tree to estimate the average length of short shoots per tree. Destructive samples of spurs with short bourses, short laterals, and long shoots were collected from extra trees to obtain regressions between length and leaf area measurements. Final leaf area per tree was calculated by summing the total number multiplied by the estimated leaf area of short spurs and laterals, and long shoots per tree. Total shoot length per tree was calculated to estimate vegeta- tive growth of all trees in the year treatments were applied.

At harvest (140 DAB, 3 Oct.), fruit number, and total and mean fruit weight per tree were determined.

Leaf and whole-canopy gas exchange. Gas exchange rates were monitored periodically during the growing season of 1994, including periods before and after mite development on the trees. Only $\mathrm{CO}_{2}$ exchange data collected after mite development are reported here.

Leaf gas exchange was measured under clear, sunny conditions between 8:30 and 14:00 solar time with a CIRAS-1 portable opensystem gas analyzer (PP-Systems, Hitchin, Herts, U.K.) with a leaf cuvette that includes $2.5 \mathrm{~cm}^{2}$ of leaf area. On 29 and $30 \mathrm{Aug}$. and 20 and 21 Sept. (105, 106, 127 and 128 DAB), leaf NCER was measured from four (first three dates) or six (last date) leaves, divided equally among well-exposed midextension shoot leaves and well-exposed bourse leaves on spurs, that had representative visual mite damage for each tree. Overall weighted average for all days of measurements was calculated for each tree to account for differences in number of leaves measured on different dates.

Whole-canopy NCER was monitored by enclosing eight trees inside eight identical whole tree chambers made of sheets of clear Mylar plastic in an open-system similar to the method of Corelli Grappadelli and Magnanini (1993), modified by Lakso et al. (1996). Each chamber of about 9400 L was kept inflated by an average air flow rate of $11,000 \mathrm{~L} \cdot \mathrm{min}^{-1}$ brought into the chamber by a $15 \mathrm{~cm}$ SDR 35 PVC pipe connected to a shaded pole blower (1030 rpm, 6.8 amperes, Dayton Electric Manufacturing Co., Chicago). A desirable range of $\Delta \mathrm{CO}_{2}$ of 10 to $30 \mathrm{ppm}$ between the inlet and the outlet, and a maximum increase of $3{ }^{\circ} \mathrm{C}$ inside the chamber occurred. A manifold made of $15 \mathrm{~cm}$ round flexible aluminum duct was put at the end of the PVC pipe near the trunk of the tree to promote good air mixing inside the chamber. At the inlet and outlet, temperature and relative humidity were measured with a thermo-hygrometer probe (Solomat model 355RHX) attached to a MPM500e (Solomat Neotronics Co., Norwalk, Conn.), while $\mathrm{CO}_{2}$ concentrations were measured with a LCA2 infrared gas-analyzer (ADC Inc., Hoddesdon, Herts, U.K.). Air velocity was measured by placing a hot wire anemometer probe (Solomat model 127MSX) through an access hole, at the center of the air flow, in the inlet pipe and at $1 \mathrm{~m}$ distance from the base of the chamber. Calibration of anemometer readings to flow rates was

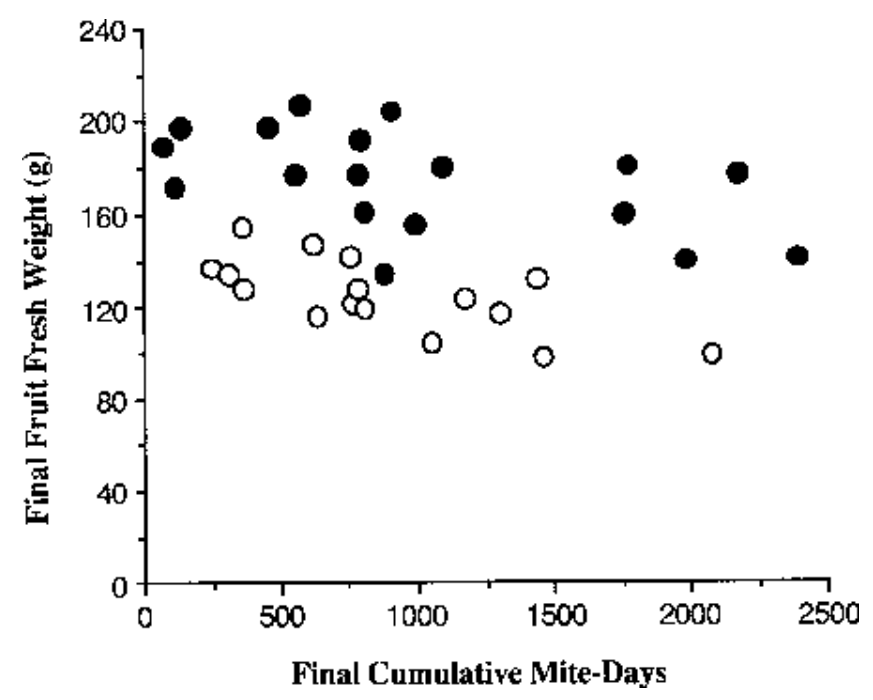

Fig. 4. Relationship between final fruit fresh weight and European red mite final cumulative mite-days of 'Starkrimson Delicious' apple trees. Data from 1992 (Lakso et al., 1996) (open circles) and from our trial (solid circles). 


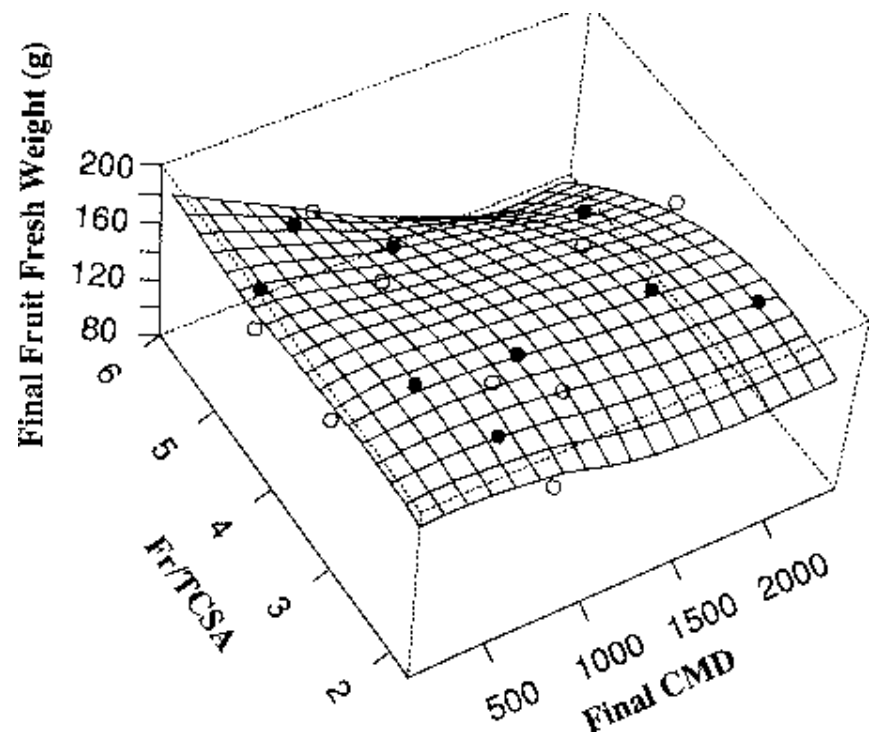

Fig. 5. Local regression surface fitted to our data on final fruit fresh weight vs. number of fruit $/ \mathrm{cm}^{2}$ trunk cross-sectional area (Fr/TCSA) and European red mite final cumulative mite-days (CMD) on 'Starkrimson Delicious' apple trees. $R^{2}=$ $0.88, P<0.002$, Error $\mathrm{df}=10$. Solid and open circles are data above and below the surface, respectively.

done with dilution of $\mathrm{CO}_{2}$ injections of known concentration and flow. Photosynthetic photon flux was measured with a quantum sensor (LI-185A; LI-COR, Lincoln, Neb.) positioned perpendicular to the sun.

Whole-canopy NCER was measured under clear, sunny conditions on 16, 19, 23, 24, 29, and 30 Aug. and 20 and 21 Sept. (92, $95,99,100,105,106,127$, and 128 DAB). Typically, eight trees were enclosed in chambers in the morning and readings were taken hourly throughout the day. The chambers were then removed and installed on other eight trees the next sunny day for more measurements. During the next sunny days, slightly different sets of eight trees were measured on each day, because only sixteen out of the eighteen experimental trees could be measured on each couple of sunny days. One, four and thirteen trees were measured during 2, 3 and $4 \mathrm{~d}$, respectively, over the season. Average of readings of whole-canopy NCER for each day and for all measured days was calculated for each tree.

Return bloom and cropping in 1995. Return bloom was determined in May 1995 by counting all flower clusters per tree, except lateral flower clusters that were of minimal occurrence $(<5 \%$ of all clusters) and usually do not set fruit. Number of fruit per tree the year following treatment was determined by counting total number of fruit per tree on 20 July 1995 . No thinning treatment was applied in 1995. Return bloom and fruiting were expressed on a per tree basis and crop load effects were also expressed as fruit/tree. An outlier tree that had a light crop and a medium mite population in 1994 showed abnormally low return bloom and cropping. That tree was removed from the data for analyses because it showed an abnormally light bloom compared to the average of the remaining trees in the orchard for the past 5 years.

Statistical analyses. Because individual crop loads and ERM populations were measured and not simply categorized, the data were analyzed with regression techniques. JMP (SAS Institute, Cary, N.C.) was used for simple regression analysis, Genstat (NAG, Downers Grove, Ill.) for fitting exponential regressions, and SPLUS (StatSci, Seattle, Wash.) for fitting and plotting local regression surfaces (Cleveland and Devlin, 1988). Local regression techniques are useful for describing data without making strong assumptions about the shape as do traditional response surfaces. Any given neighborhood of the predictor space is fitted but there is no overall equation (Cleveland and Devlin, 1988).

\section{Results and Discussion}

Mite development. Mite populations increased in late July and early Aug. (75 to $85 \mathrm{DAB}$ ), with a range of final cumulative mitedays from 69 to 2394 CMD. By mid Aug. (91 DAB) mite populations on all trees were killed by acaricide sprays. Trees had CMD lower, near and above the currently recommended tolerable CMD level of 500 (Fig. 1). Peak populations ranged from an average of 5 to 156 mites/leaf among trees in early August.

Crop load. Crop load ranged from 1.7 to 5.9 fruit/TCSA, which corresponded to 119 to 310 fruit/tree (fruit/tree). Crop load was expressed in terms of fruit/TCSA because of some variation in tree size and because fruit size before mite population developed was better related to fruit/TCSA than to fruit/tree in this orchard. Leaf area per tree ranged from 11.5 to $26.4 \mathrm{~m}^{2}$. Fruit : leaf area ratios per tree ranged from 0.047 to 0.181 fruit $/ \mathrm{m}^{2}$ of leaf area or from 2126 to 552 square centimeters of leaf area per fruit.

Seasonal fruit growth, final fruit weight, and yield as affected by CMD and fruit/TCSA. Seasonal fruit growth curves of four trees representing extreme cases of lightly and normally cropped trees subjected to low and high mite populations illustrate how mite and crop load affected fruit growth throughout the season (Fig. 2). Trees were selected on the basis of similar fruit size within each crop load level before the development of mite populations. Thus, any differences in fruit growth later in the season between healthy and mite infested trees with similar crops could be attributed mainly to mite damage. As a result of the thinning treatments, lightly cropped trees had higher initial fruit growth rates than normally cropped trees, leading to larger fruit on lightly cropped trees at harvest. Fruit growth reductions due to mites were noticeable earlier and more severely on normally cropped trees than on lightly cropped trees (Fig. 2). Repeated measurement analysis of variance supported this observation: significant divergence of fruit growth rates due to mites occurred at $86 \mathrm{~d}$ in normally and $93 \mathrm{~d}$ on

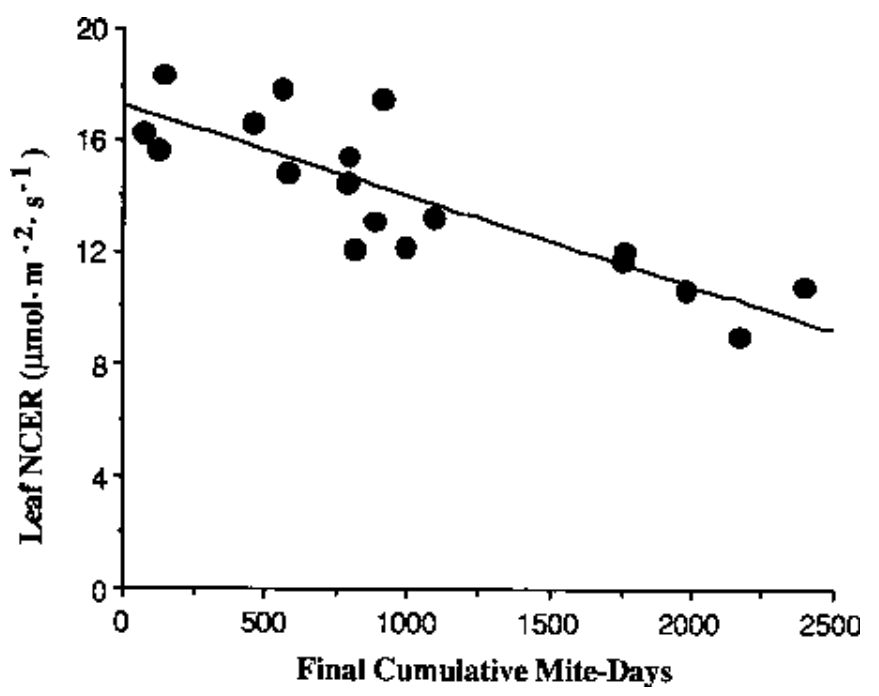

Fig. 6. Relationship between leaf net $\mathrm{CO}_{2}$ exchange rate (NCER) and European red mite final cumulative mite-days (CMD) on 'Starkrimson Delicious' apple trees. Leaf NCER $=17.22-0.0032 \mathrm{CMD}, r^{2}=0.71, P<0.0001$. 


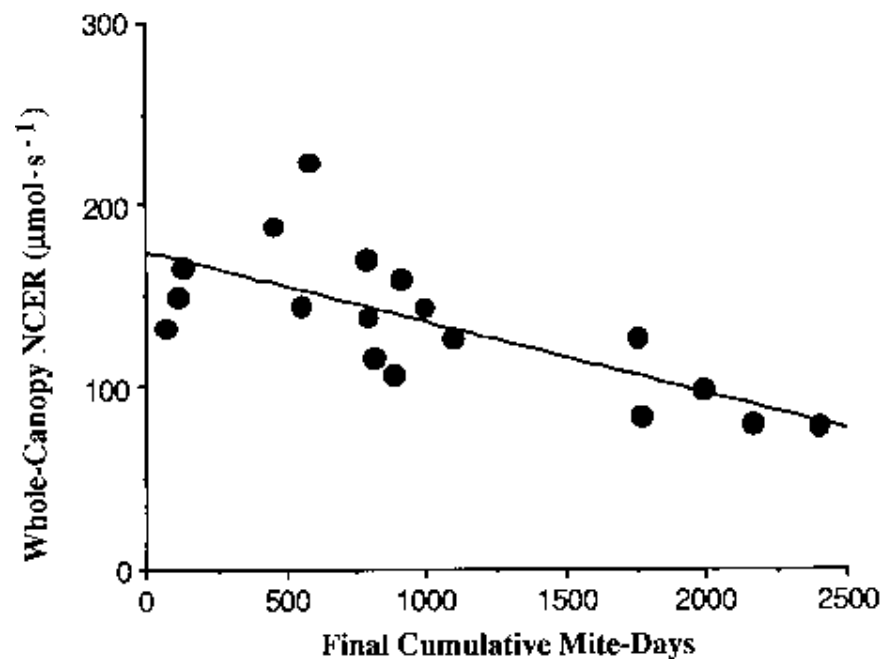

Fig. 7. Relationship between whole-canopy net $\mathrm{CO}_{2}$ exchange rate (NCER) and European red mite final cumulative mite-days (CMD) on 'Starkrimson Delicious' apple trees. Whole-canopy NCER $=173.96-0.039 \mathrm{CMD}, r^{2}=0.52, P<0.001$.

lightly cropped trees.

Final fruit weight decreased as CMD increased, although only $28 \%$ of the variation was explained by CMD alone (Fig. 3). Differences in crop load were certainly one of the reasons for scattering of the data. As fruit/TCSA increased, fruit size decreased as expected [fruit weight $(\mathrm{g})=220.53-12.70$ fruit/TCSA, $\left.r^{2}=0.49\right]$. Our data were compared with data obtained in 1992 in the same orchard with various mites levels on trees without major variation in crop load in that year (Lakso et al., 1996) (Fig. 4). Although absolute values differed, the general relationship (i.e., the slope of the regression line) between fruit weight and CMD did not differ significantly between both years. Smaller fruit in 1992 compared to 1994 were mainly because crop load was in general higher in 1992 than in 1994. An abnormally cold and rainy summer in 1992 may also have contributed to smaller fruit size in 1992. Data was scattered and no threshold was apparent in 1992 and 1994. These results are consistent with highly variable effects of ERM on apple fruit size previously reported (Beers and Hull, 1990; Beers et al., 1987; Chapman et al., 1952; Hull and Beers, 1990; Lakso et al., 1996; Light and Ludlam, 1972; Marini et al., 1994; Zwick et al., 1976).

A local regression surface was fitted to the mite and crop load data from all trees and showed a nonlinear interaction between crop load and CMD effects on final fruit weight (Fig. 5). As CMD increased, there was a greater reduction in fruit size on normally cropped trees than on lightly cropped trees, confirming earlier findings of Ames et al. (1984) and Marini et al. (1994). Interactive effects of crop load and mites on fruit growth and final fruit size were similar to interactions of shading and crop load or developmental stage of crop during season (Lakso and Corelli Grappadelli, 1992; Lakso et al., 1989), suggesting that carbon balance may mediate the effects of crop load, mite stress and low light. Simulations of seasonal patterns of carbon supply/demand on apple trees have shown that heavily cropped trees tend to show carbon deficit for fruit growth earlier in the season than lightly cropped trees (Lakso and Corelli Grappadelli, 1992). Therefore a reduction in carbon supply due to shade or mites can cause more drastic effects on heavily cropped trees than on lightly cropped trees.

There was no interaction of crop load and mites on yield $(\mathrm{kg} /$ tree), probably because fruit size is less important than number of fruit per tree in determining yield (Forshey and Elfving, 1977).
When fruit numbers were differentially adjusted by hand-thinning, potential yields were varied, confounding any possible effects of mites on yield. The primary effect of mite infestation was to affect yield via fruit size.

Vegetative growth as affected by CMD and fruit/TCSA. Mites and the range of crop loads in this study had no significant effects on total shoot length per tree (data not shown), as also reported by Beers and Hull (1987, 1990). Because shoot growth ceased by midsummer (Forshey and Elfving, 1989) and mite population increased around that time, mites were not expected to affect total shoot length. Rogers and Booth (1964) also found no effect of crop load on current shoot length but a negative correlation occurred between crop and following year's shoot growth of one apple cultivar on four out of five rootstocks tested over 25 years. Barlow (1964) found reduction of current and subsequent year's shoot growth in cropping compared to noncropping trees, but those were extreme cases.

Leaf and whole-canopy gas exchange as affected by CMD and fruit/TCSA. ERM caused reductions in leaf NCER measured after target CMD were achieved (Fig. 6) as previously reported by Campbell and Marini (1990), Campbell et al. (1990), Lakso et al. (1996) and Mobley and Marini (1990). Based on the fitted linear regression of our data, trees with $2000 \mathrm{CMD}$ had about $60 \%$ to $65 \%$ leaf NCER of trees with 0 CMD.

Mite also reduced whole-canopy NCER (Fig. 7). When scaling up from leaf to whole-canopy NCER, a lower percentage of variability could be attributed to CMD. This was expected because whole-canopy NCER integrates the NCER of the whole population of leaves and also the respiration of the branches and fruit of each tree. Based on the fitted linear regression, trees with 2000 CMD had about 55\% whole-canopy NCER of trees with 0 CMD. The pattern of leaf and whole-canopy NCER reductions due to mites is similar to what Lakso et al. (1996) found, even though the absolute values differ somewhat. Those differences could be attributed to variations in the environment, plant physiological conditions and mite development between these experiments.

Crop load variation had no significant effect on leaf or canopy NCER. Similarly, Palmer (1986) observed that flower thinning resulting in final yield reductions of $30 \%$ and $56 \%$ did not show consistent effects on leaf NCER in mid to late season. Fruit influenced whole-canopy NCER (Butler and Landsberg, 1981;

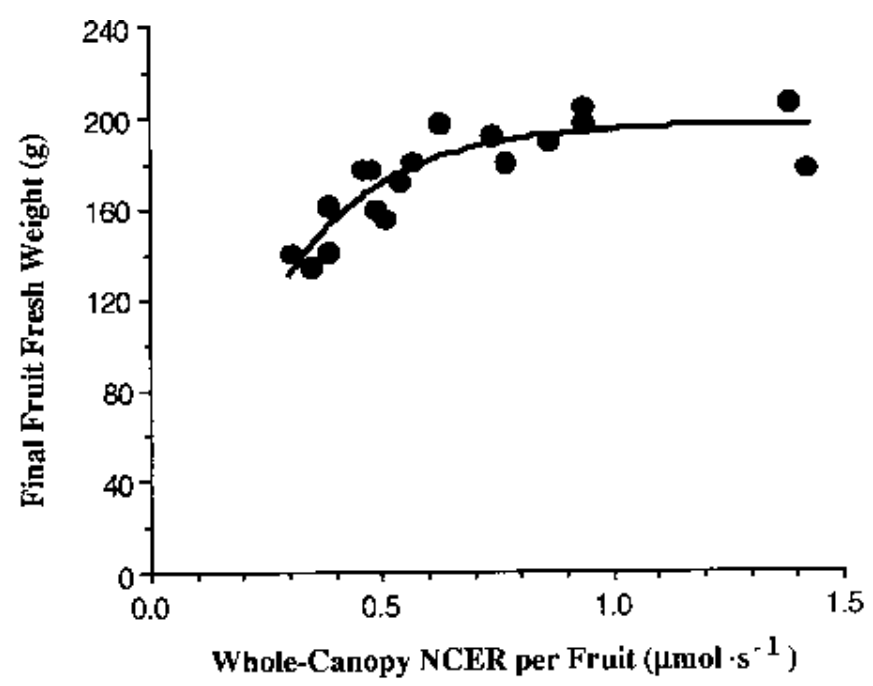

Fig. 8. Relationship between final fruit fresh weight and whole-canopy net $\mathrm{CO}_{2}$ exchange rate (NCER) per fruit of 'Starkrimson Delicious' apple trees in 1994. Fruit weight $=196.42-277 \times 0.009$ Canopy NCER/fruit, $r^{2}=0.77, P<0.001$. 


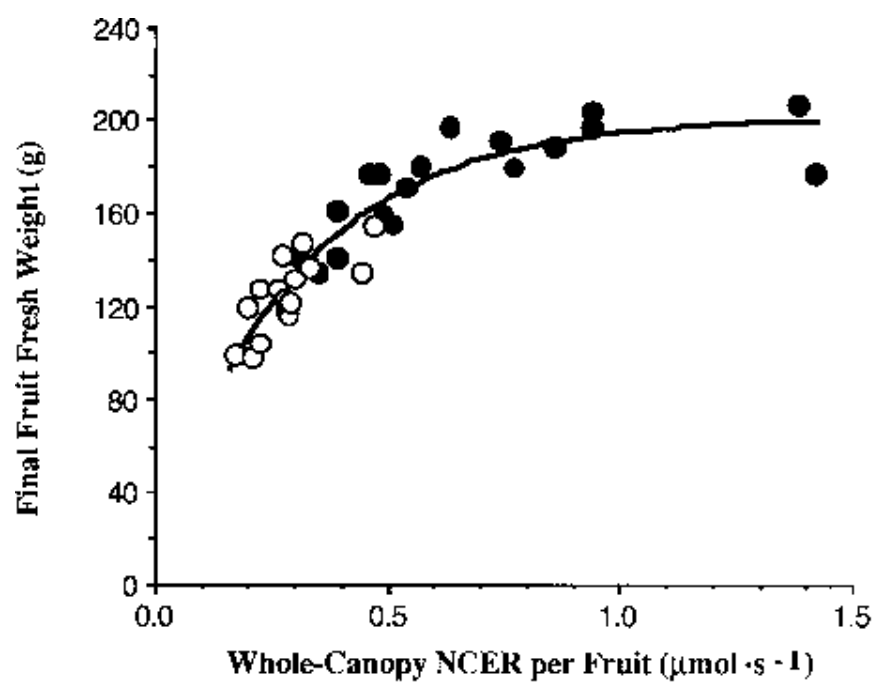

Fig. 9. Relationship between final fruit fresh weight and whole-canopy net $\mathrm{CO}_{2}$ exchange rate (NCER) per fruit of 'Starkrimson Delicious' apple trees. Fruit weight $=201.06-185.5 \times 0.0363^{\text {Canopy NCER/fruit }}, r^{2}=0.88, P<0.001$. Data from 1992 (Lakso et al., 1996) (open circles) and from our trial (solid circles).

Wibbe et al., 1993). However, those were extreme cases involving apple trees with and without fruit and no information on the actual crop load being evaluated was provided.

Even though the effects of the applied pesticides on the NCER of the experimental trees was not evaluated, pesticides may or may not affect NCER of apple leaves (Ayers and Barden, 1975). In our trial, most pesticide treatments were the same for all trees, except for one oil spray in early May and one propargite (Omite) spray in early July on the low mite (<100 CMD) trees. We think that our results comparing the relative behavior of all trees were not confounded by potential pesticide effects on NCER because 1) oil was sprayed at tight cluster, causing no visible injury to leaves, and Omite does not seem to affect leaf NCER (Ayers and Barden, 1975), and 2) NCER measured after the application of those two specific treatments and before any mite injury were similar for all trees.

Final fruit weight as affected by Canopy NCER/fruit. If carbon balance is the mechanism of differential response to ERM in lightly and normally cropped apple trees, a parameter that integrates the carbohydrate supply/demand balance of the tree should relate better to final fruit size than CMD alone. We used wholecanopy NCER per fruit in middle to late season as an indicator of carbohydrate availability to the fruit, as previously done by Lakso et al. (1996), because fruit are the major sinks for carbohydrates at that time of the season (Forshey and Elfving, 1989). An exponential regression fitted to our data showed a very good relationship between fruit weight and late season canopy NCER per fruit $\left(r^{2}=\right.$ 0.77) (Fig. 8). Furthermore, when data from (Lakso et al., 1996) and ours were pooled, the relationship was maintained $\left(r^{2}=0.88\right)$ (Fig. 9). The negative exponential model, which fitted our biological data the best, was a continuous model but for practical purposes no changes in fruit weight occurred as whole-canopy NCER per fruit was reduced from 1.5 to about $0.6 \mu \mathrm{mol} \cdot \mathrm{s}^{-1}$. After reaching that level, any further decrease in whole-canopy NCER per fruit seemed to cause a greater decrease in fruit weight. This type of response was in practice similar to the threshold type of response used in IPM, in which plants can tolerate a certain level of foliar injury before the crop is affected.

The variable effects of CMD on fruit weight (Fig. 4) clearly indicates that by considering the pest only, it was difficult to determine plant responses to the foliar pest. When we took a more integrated approach and looked at the whole-canopy NCER per fruit (Fig. 9), however, we could explain variations in fruit growth responses of apple trees to mites more adequately over different years and various crop loads. Furthermore, our mechanistic model using whole-canopy NCER per fruit was almost as good a predictor of fruit weight as our empirical local surface regression including crop load and mite levels. This is strong evidence that carbohydrate supply/demand is a good integrator of the environment/ plant/mite complex and may be the main mechanism of apple tree responses to single and multiple foliar pest stresses. Similar type of studies need to be done in different apple systems with other foliar feeders to determine if carbohydrate supply/demand is also the mechanism for those situations.

Return bloom and cropping in 1995 as affected by CMD and fruit/tree. CMD alone had no significant effect on return bloom and cropping in 1995 (Figs. 10A and 11A). When comparing our data with return bloom and cropping data of 1993 obtained by Lakso et al. (1996), the lack of relationship with CMD persisted (Figs. 10A and 11A). When regressed against crop load alone the $r^{2}$ was 0.64 for return bloom and 0.50 for return fruit per tree (data not shown). A local regression surface showing an interaction
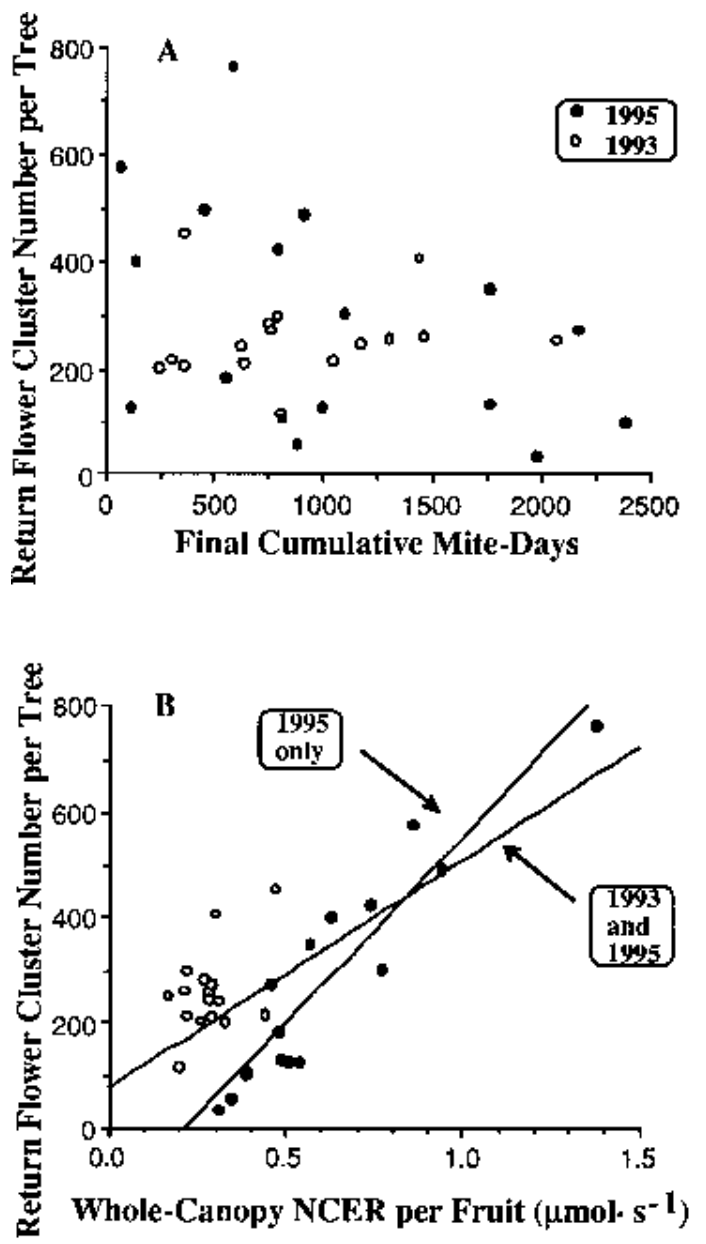

Fig. 10. Relationship between return flower cluster number per tree and (A) final cumulative mite-days, and (B) whole-canopy net $\mathrm{CO}_{2}$ exchange rate (NCER) per fruit of 'Starkrimson Delicious' apple trees. Linear regression models for $\mathbf{B}$ are Return flower cluster number per tree in $1995=-156.49+706.54$ Canopy NCER per fruit, $r^{2}=0.88, P<0.0001$ (our data only); and Return flower cluster number per tree in 1993 and $1995=75.25+430.93$ Canopy NCER per fruit, $r^{2}=0.54, P$ $<0.0001$ (pooled data). Return bloom and cropping data from 1993 (Lakso et al., 1996) (open circles) and from our trial (solid circles). 

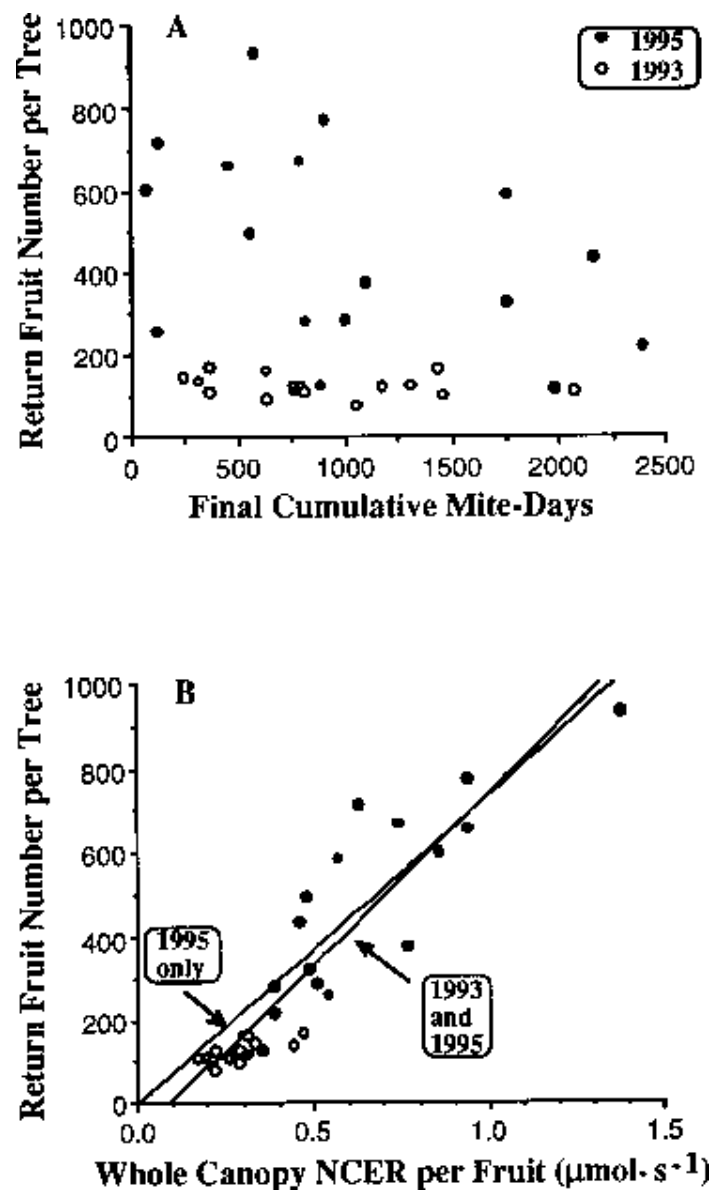

Fig. 11. Relationship between return fruit number per tree and (A) final cumulative mite-days and (B) whole-canopy net $\mathrm{CO}_{2}$ exchange rate (NCER) per fruit of 'Starkrimson Delicious' apple trees. Linear regression models for $\mathbf{B}$ are Return fruit number per tree in 1995 $=-6.61+739.67$ Canopy NCER per fruit, $r^{2}=0.73$, $P<0.0001$ (our data only). Return fruit number per tree in 1993 and $1995=-80.56$ +816.06 Canopy NCER per fruit, $r^{2}=0.83, P<0.0001$ (pooled data). Return bloom and cropping data from 1993 (Lakso et al., 1996) (open circles) and from our trial (solid circles).

between CMD and crop load was the best fit with $R^{2}$ of 0.90 and 0.74 for return bloom and fruiting, respectively (Fig. $12 \mathrm{~A}$ and B). Trees with low CMD and a light crop tended to have higher return bloom and cropping than the remaining treatments. Those were the same trees that had higher fruit size the previous year and likely had a better carbohydrate supply/demand balance in 1994. Return crop was highly positively correlated to return bloom $\left(r^{2}=0.88\right)$. Inhibition of flowering and cropping the following year due to heavy cropping has been extensively documented and reviewed by Buban and Faust (1982) and Forshey and Elfving (1989). However, the mechanism of that effect (hormones, carbohydrates or nutrients) has not been fully elucidated. Flower bud initiation in spurs usually occurs three to six weeks after bloom the year before those buds open, but flower development continues until the next growing season (Buban and Faust, 1982; Forshey and Elfving, 1989; Pratt, 1988). Even though late season mite infestation would not be expected to have major effects on return bloom, reduced bloom the year following mite infestation as observed in our study have been previously reported in some but not all cases (Beers and Hull, 1987; Beers and Hull, 1990; Hull and Beers, 1990; Lakso et al., 1996). Reduced return cropping due to mites have been observed in some cases but not in others (Beers and Hull, 1990; Beers et al. 1990; Hull and Beers, 1990; Lakso et al., 1996). Variations in carbohydrate status of the trees and on the degree of overlap between mite attack and flower bud differentiation and development could be related to different mite effects on return bloom and cropping. Mite and crop load studies including flower bud sampling throughout the season would help elucidate this question.

Return bloom and cropping in 1995 as related to Canopy NCER/fruit. A positive correlation was found between wholecanopy NCER per fruit and return bloom and cropping, in 1995, with $r^{2}$ of 0.88 and 0.73 , respectively (Figs. 10B and 11B). When data from Lakso et al. (1996) and our data were pooled, the $r^{2}$ of the linear regression between return bloom and whole-canopy NCER per fruit went down to 0.54 and that regression was significantly different from the regression with our data alone (Fig. 10B). The correlation and the slope of the regression between return cropping and whole-canopy NCER per fruit for the pooled data, however, were similar to our data alone $\left(r^{2}=0.83\right)$ (Fig. 11B). It is likely that other factors besides late season canopy NCER per fruit play an important role in bloom initiation and/or development. It is not clear why return bloom related to whole-canopy NCER per fruit in our experiment and not in the trial of Lakso et al. (1996). One possible explanation is that the abnormal low radiation and high precipitation in June and July of 1992 affected flower bud initiation
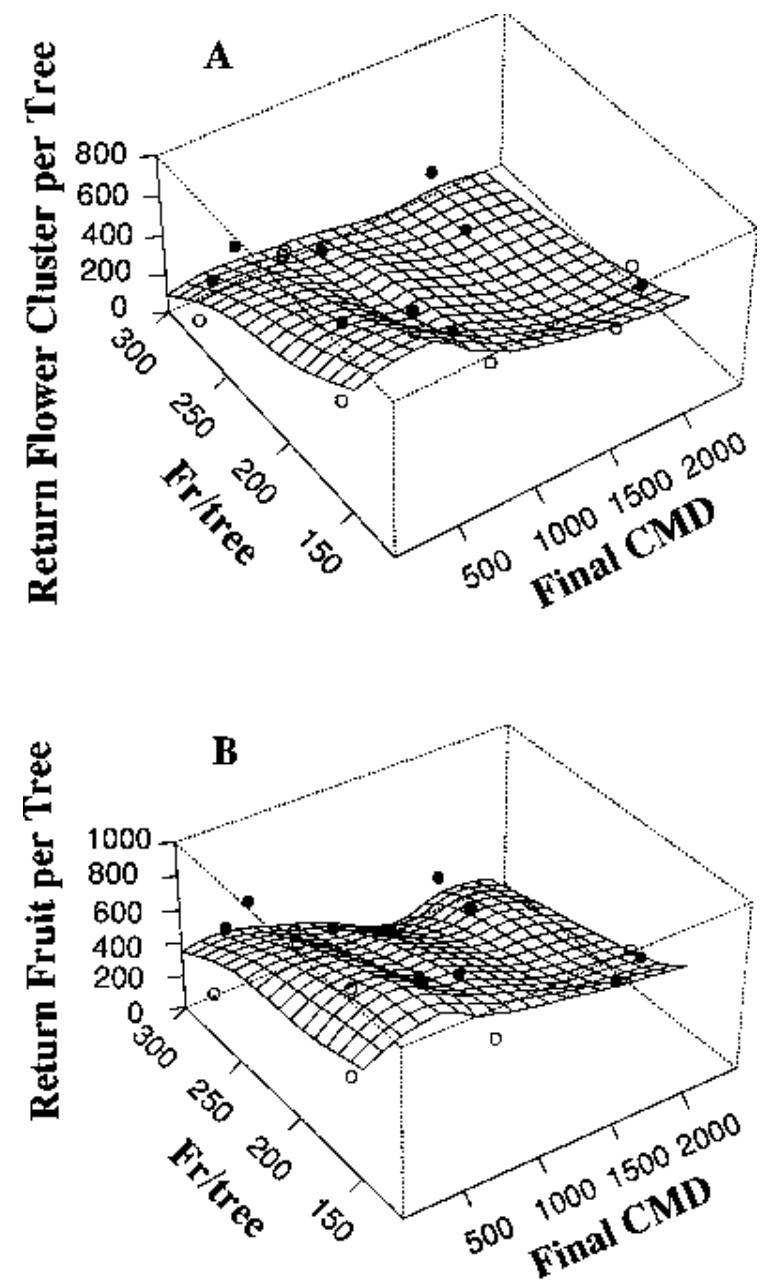

Fig. 12. Local regression surfaces fitted to our data on return flower cluster number per tree (A) and return fruit number per tree (B) in 1995 vs. number of fruit per tree (Fr/ tree) and European red mite final cumulative mite-days (CMDs) on 'Starkrimson Delicious' apple trees. $R^{2}=0.90, P<0.002$ (A) and $R^{2}=0.74, P<0.006$ (B). Error df $=9$ for both surfaces. Solid and open circles are data above and below the surface, respectively. 
and differentiation in a different way compared to the sunny and warm summer of 1994. Both years' return cropping, which relates to both number of flowers per tree and fruit retention, was more closely correlated than return bloom to the expression of carbohydrate supply and demand balance to the fruit the previous year. These results suggest that a low canopy NCER per fruit late in the previous year has a detrimental effect on flower development for the next year resulting in poor return crop load. Carry-over effects of mites and crop load are certainly more complex than fruit size responses. More physiological studies are needed to help elucidate the complex interactions among crop load, mites and environment on return bloom and fruiting of apples.

Implications for integrated pest management on apples are as follows:

1) Final fruit size on trees bearing a good commercial crop showed a more severe reduction due to mite stress than on lightly cropped trees. Thus, it is important to follow the current sampling and threshold recommendations very strictly when crop load is moderate, when fruit size is already limited compared to lightly cropped trees. For heavier crop loads, action thresholds may need to be reduced.

2) Carbohydrate supply/demand balance explained the variability in fruit size, return bloom and return crop load responses of apple trees to ERM injury better than cumulative mite-days alone. Thus research on pest effects on fruit trees for determination of action thresholds of foliar pests should consider host plant physiological aspects such as crop load.

\section{Literature Cited}

Ames, G.K., D.T. Johnson, and R.C. Rom. 1984. The effect of European red mite feeding on the fruit quality of 'Miller Sturdeespur' apple. J. Amer. Soc. Hort. Sci. 109:834-837.

Ayers, Jr., J.C. and J.A. Barden. 1975. Net photosynthesis and dark respiration of apple leaves as affected by pesticides. J. Amer. Soc. Hort. Sci. 100:24-28.

Barlow, H.W.B. 1964. An interim report on a long-term experiment to assess the effect of cropping on apple tree growth. Rpt. E. Malling Res. Sta. 1963:84-93.

Beers, E.H. and L.A. Hull. 1987. Effect of European red mite (Acari:Tetranychidae) injury on vegetative growth and flowering of four cultivars of apples. Environ. Entomol. 16:569-574.

Beers, E.H. and L.A. Hull. 1990. Timing of mite injury affects the bloom and fruit development of apple. J. Econ. Entomol. 83:547-551.

Beers, E.H., L.A. Hull, and G.M. Greene. 1990. Effect of a foliar urea application and mite injury on yield and fruit quality of apple. J. Econ. Entomol. 83:552-556.

Beers, E.H., L.A. Hull, and J.W. Grimm. 1987. Relationships between leaf:fruit ratio and varying levels of European red mite stress on fruit size and return bloom of apple. J. Amer. Soc. Hort. Sci. 112:608-612.

Buban, T. and M. Faust. 1982. Flower bud induction in apple trees: Internal control and differentiation. Hort. Rev. 4:174-203.

Butler, D.R. and J.J. Landsberg. 1981. Respiration rates of apple trees, estimated by $\mathrm{CO}_{2}$-efflux measurements. Plant Cell Environ. 4:153-159.

Campbell, R.J. and R.P. Marini. 1990. Nitrogen fertilization influences the physiology of apple leaves subjected to European red mite feeding. J. Amer. Soc. Hort. Sci. 115:89-93.

Campbell, R.J., K.N. Mobley, and R.P. Marini. 1990. Growing conditions influence mite damage on apple and peach leaves. HortScience 25:445448.

Chapman, P.J., S.E. Lienk, and O.F. Curtis Jr. 1952. Responses of apple trees to mite infestations: I. J. Econ. Entomol. 45:815-821.

Cleveland, W.S. and S.J. Devlin. 1988. Locally-weighted regression: an approach to regression analysis by local fitting. J. Amer. Statist. Assn. 83:596-610.

Coghill, K.J. 1969. The effect of fruit tree red spider mite on yields of apple. Proc. 5th Br. Insectic. Fungic. Conf.:495-499.
Croft, B.A. 1978. Potentials for research and implementation of integrated pest management on deciduous fruit trees, p. 101-115. In: E.H. Smith and D. Pimentel (eds.). Pest control strategies. Academic Press, New York.

Corelli Grappadelli, L. and E. Magnanini. 1993. A whole tree system for gas exchange. HortScience 28:41-45.

Croft, B.A., S.C. Hoyt, and P.H. Westigard. 1987. Spider mite management on pome fruits, revisited: organotin and acaricide resistance management. J. Econ. Entomol. 80:304-311.

Forshey, C.G. and D.C. Elfving. 1977. Fruit numbers, fruit size, and yield relationships in 'McIntosh' apples. J. Amer. Soc. Hort. Sci. 102:399-402.

Forshey, C.G. and D.C. Elfving. 1989. The relationship between vegetative growth and fruiting in apple trees. Hort. Rev. 11:229-287.

Hansen, P. and V.J. Christensen. 1974. Fruit thinning. III. Translocation of ${ }^{14} \mathrm{C}$ assimilates to fruit from near and distant leaves in the apple 'Golden Delicious'. Hort. Res. 14:41-45.

Hull, L.A. and E.H. Beers. 1990. Validation of injury thresholds for European red mite (Acari: Tetranychidae) on 'Yorking' and 'Delicious' apples. J. Econ. Entomol. 83:2026-2031.

Lakso, A.N., L. Corelli Grappadelli, J. Barnard, and M.C. Goffinet. 1995. An expolinear model of the growth pattern of the apple fruit. J. Hort. Sci. 70:389-394.

Lakso, A.N., G.B. Mattii, J.P. Nyrop, and S.S. Denning. 1996. Influence of European red mite on leaf and whole-canopy carbon dioxide exchange, yield, fruit size, quality, and return cropping in 'Starkrimson Delicious' apple trees. J. Amer. Soc. Hort. Sci. 121:954-958

Lakso, A.N. and L. Corelli Grappadelli. 1992. Implications of pruning and training practices to carbon partitioning and fruit development in apple. Acta Hort. 322:231-239.

Lakso, A.N. and R.S. Johnson. 1990. A simplified dry matter production model for apple using automatic programming simulation software. Acta Hort. 276:141-148.

Lakso, A.N., T.L. Robinson, and R.M. Pool. 1989. Canopy microclimate effects on patterns of fruiting and fruit development in apples and grapes, p. 263-274. In: C.J. Wright (ed.). Manipulation of fruiting. Butterworths, London.

Lathrop, F.H. 1951. Sidelights on European red mite control. J. Econ. Entomol. 44:509-514.

Lienk, S.E. and J.C. Minns. 1980. Effect of early mite feeding on apple. Proc. N.Y. State Hort. Soc. 125:93-96.

Light, W.I.St.G. and F.A.B. Ludlam. 1972. The effects of fruit tree red spider mite (Panonychus ulmi) on yield of apple trees in Kent. Plant Pathol. 21:175-181.

Marini, R.P., D.G. Pfeiffer, and D.S. Sowers. 1994. Influence of European red mite (Acari:Tetranychidae) and crop density on fruit size and quality and on crop value of 'Delicious' apples. J. Econ. Entomol. 87:1302-1311.

Mobley, K.N. and R.P. Marini. 1990. Gas exchange characteristics of apple and peach leaves infested by European red mite and twospotted spider mite. J. Amer. Soc. Hort. Sci. 115:757-761.

Palmer, J.W. 1986. Seasonal variation of light saturated photosynthetic rate of Golden Delicious apple leaves as influenced by leaf type and crop load, p. 30-33. In: A.N. Lakso and F. Lenz (eds.). The Regulation of Photosynthesis in Fruit Trees. N.Y. State Agr. Expt. Sta., Geneva, Spec. Publ.

Palmer, J.W., Y.-L. Cai, and Y. Edjamo. 1991. Effect of part-tree flower thinning on fruiting, vegetative growth and leaf photosynthesis in 'Cox's Orange Pippin' apple. J. Hort. Sci. 66:319-325.

Pedigo, L.P. 1989. Entomology and pest management. Macmillan, New York.

Pratt, C. 1988. Apple flower and fruit: morphology and anatomy. Hort. Rev. 10:273-308.

Redl, H., A. Hiebler, J. Jerabek, and K. Eckel. 1991. Auswirkungen gestaffelter befallsdichten und verweilzeiten von spinnmilben auf den apfelertrag und die apfelqualitat. Mitteilungen Klosterneuburg 41:238248.

Rogers, W.S. and G.A. Booth. 1964. Relationship of crop and shoot growth in apple. J. Hort. Sci. 39:61-65.

Wibbe, M.L., M.M. Blanke, and F. Lenz. 1993. Effect of fruiting on carbon budgets of apple tree canopies. Trees: Structure and Function 8:56-60.

Zwick, R.W., G.J. Fields, and W.M. Mellenthin. 1976. Effects of mite population density on 'Newtown' and 'Golden Delicious' apple tree performance. J. Amer. Soc. Hort. Sci. 101:123-125. 